\title{
Parents, Teach Your Children Well
}

Hookah smoking is rapidly increasing in popularity in the United States, particularly among urban youth, college students, and young professionals. The most common prevalence is among ages 18-24 y. Alarmingly, some studies suggest there is significant use among middle and high school students as well. ${ }^{1}$ Hookahs are water pipes that are used to smoke tobacco heated by charcoal. Hookah tobacco comes in many different enticing flavors and is also known as narghile, arghileh, shisha, hubble-bubble, and goza. Hookah smoking is a social event, typically done in small groups among people who share the mouthpiece. New forms of hookah smoking recently introduced to the marketplace include steam stones and hookah pens. These devices use battery power to turn liquid containing nicotine, flavorings, and other chemicals into a vapor that is inhaled. The health risks of charcoal-heated tobacco during hookah smoking are well known, but very little is known about the risks of electronic hookah smoking. ${ }^{2}$

The study reported in this issue of RESPIRATORY CARE by Calvanese et $\mathrm{al}^{3}$ reveals disturbing facts about the lack of parental understanding of the dangerous health effects of hookah use among their college-age children attending a private college in the Southeast United States. Although hookah smokers are likely to heed their parents' message, these parents misunderstand hookah smoking, making them ill-prepared to advise their children of the health dangers. Regrettably, most national and state surveys of tobacco use do not include hookah use as a data point, so information and public awareness are limited. Adding to the lack of understanding is the rapidly changing marketplace that provides consumers with a wide assortment of increasingly diverse products that deliver nicotine with or without combustible tobacco. As the investigators suggest, increased awareness among parents and children-and I would add, the general public - is desperately needed. Many misconceptions exist about hookah-smoking health risks. Targeted education must be provided to stop the

Dr Boone has disclosed no conflicts of interest.

Correspondence: Erna Boone DrPH RRT FAARC, Department of Respiratory and Surgical Technologies, College of Health Professions, University of Arkansas for Medical Sciences, 4301 W Markham Street, 737, Little Rock, AR 72205. E-mail: booneernal@uams.edu.

DOI: $10.4187 /$ respcare. 04236 dramatic rise in hookah use in the United States. It is imperative that parents have appropriate information to teach their children about these hazards.

First, parents should teach their children that hookah smoking has the same health risks as cigarette smoking, plus additional risks that smoking does not have. The perception of safety and harm reduction has been disproven by studies that documented the presence of toxicants and carcinogens in water-pipe smoke. ${ }^{4}$ An hour-long hookahsmoking session involves 200 puffs of burned tobacco, compared with 20 puffs when smoking one cigarette. The amount of smoke inhaled during a typical hookah session is $\sim 90,000 \mathrm{~mL}$, compared with $500-600 \mathrm{~mL}$ inhaled when smoking one cigarette. ${ }^{1}$ Thus, the occurrence of adverse health effects primarily on the respiratory and cardiovascular systems noted by documented cases of coronary artery disease, obstructive pulmonary disease, and increased

See the Original Study on Page 959

risk of lung cancer is not difficult to understand. Perinatal effects in smoking mothers and low birthweight and respiratory disease risk for their babies ${ }^{2}$ and periodontal disease ${ }^{4}$ have been described for hookah smokers. Hookah smoking is also associated with bladder, oral, stomach, and esophageal cancers, as well as reduced lung function and decreased fertility. Like cigarette smokers, hookah smokers suffer health risks from secondhand smoke and from the smoke emitted from the charcoal used to heat tobacco in the hookah bowl. ${ }^{2}$ Shared mouthpieces among hookah smokers have also been demonstrated to spread infectious diseases, including tuberculosis, herpes, influenza, and hepatitis. ${ }^{1}$ Parents should make their children aware of the additional hazards posed by hookah smoking over cigarette smoking.

Many hookah smokers mistakenly believe that hookah smoking is less addictive than cigarette smoking because it exposes them to less nicotine. Parents should teach their children that since hookah-smoking sessions are typically longer, considerably greater nicotine exposure likely occurs. One recent study measured cotinine in urine and estimated daily water-pipe use to be equivalent to 10 cigarettes/d. ${ }^{5}$ Another study determined that only 5\% of the nicotine is filtered out through the water in the pipe. ${ }^{1}$ Other investigators have expressed concern that hookah smoking may appeal to non-cigarette smokers or become 
a potential gateway product to regular cigarette use or dual use. ${ }^{6}$ Without doubt, hookah smoking presents an opportunity for the user to become addicted to nicotine.

A review of the global hookah-smoking trend suggests that it may "represent the second global tobacco epidemic since the cigarette." ${ }^{1}$ Hookahs are smoked in homes; they can be rented; and flavored tobacco can be purchased in bars, cafes, and lounges. Hookahs are often smoked in locations where young adults gather and try different flavors throughout an evening of smoking. Hookah smoking may be perceived as a relatively inexpensive way to get together and have fun. Marketing for hookah pipes is fairly limited to specialized shops and online stores, but cafes and bars are expanding in the United States. Two thirds of the states have hookah bars and cafes, most located near college campuses. Even states with strong smoke-free air laws have been unable to slow the rampant growth of hookah bars and cafes. California, Illinois, New York, Texas, and Virginia have the greatest number of hookah bars. ${ }^{7}$ Some of these establishments can even offer products to youth under the age of 21 , as long as alcohol is not served. ${ }^{1}$ Additionally, online chats, blogs, and other internet sites are a big part of the hookah culture in the United States. Free weekly papers and ads in college newspapers and magazines are increasingly used by business owners to target young urban adults and college students. ${ }^{7}$ Hookah-smoking establishments and accessories are becoming increasingly available to a wider consumer market. Hence, parents should be talking to their children about hazards of hookah use long before they have reached an age when they are ready to enter college.

The strongest drivers of hookah-smoking popularity are the social context in which it occurs, the attractive flavors used in the tobacco mixtures, and the misperception that it is safer than cigarette smoking. ${ }^{1}$ According to 2 published studies of youth and young adults, survey respondents believe that they will experience fewer adverse health effects from hookah smoking than from cigarette smoking. ${ }^{1}$ Furthermore, $83 \%$ of respondents to an online survey of college students who reported that they smoked a water pipe in the month before the survey indicated they had no intention to quit. Those who believed that hookah smoking could be harmful were more than twice as likely to have the intention to quit, and those who smoked for $>60$ min were less inclined to quit. ${ }^{8}$ Researchers have also reported that some users believe hookah smoke is less irritating because it is filtered through water before inhalation. ${ }^{1}$ Although most parents understand the power of peer influence, in the case of hookah smoking, the misconceptions about the health risks are enormous. These misconceptions may be exceptionally difficult to counter unless the education begins at an early age and is provided often throughout the years leading to young adulthood.

Finally, parents must understand that in spite of widespread smoke-free legislation in the United States, hookah bars are often exempt and continue to operate because they sell tobacco and are classified primarily as tobacco retail stores. ${ }^{1}$ Hookah bars often allow customers to sample the tobacco products on site. Regulation of hookah smoking has been difficult because of definitions already in place for smoking and characterizing flavors, for example. Tobacco-control advocates favor strategies that would close these loopholes, allow the FDA to assert more authority over hookah tobacco, prohibit flavoring in hookah tobacco, include questions about hookah use on national surveys, pass laws to prohibit sale of hookah tobacco and paraphernalia to minors, and establish licensure and/or zoning requirements to regulate hookah establishments. Parents would be well-served to keep abreast of these policy issues in their community and state. When they are able to exercise their rights as a voter, they should take full advantage of that right.

Existing evidence on the health risks of hookah smoking demonstrates that it is correlated with the same diseases caused by cigarette smoking, plus others. Access to hookah smoking continues to grow at an alarming rate in the United States, especially among those in the age range of $18-24 \mathrm{y}$. Hookah smoking is especially appealing to this population because of its social nature, relatively inexpensive cost, enticing flavors, and reportedly sweeter and smoother smoke. Unfortunately, many hookah smokers erroneously believe that it is safer than smoking cigarettes. More research, more data from national surveys, more public policy to regulate hookah use, and targeted campaigns to educate and inform the public are needed. Calvanese et $\mathrm{al}^{3}$ have addressed an important research gap and demonstrated in a small sample of parents a lack of awareness and a naivety about their college-age children's hookah use. They have suggested using targeted educational strategies for communities, parents, and students and additional research to further explore parental knowledge and attitudes in larger populations. I agree with this systematic approach. The impact parents could have on their adolescent, teenage, and young-adult children could be monumental. Parents, please, teach your children well.

Erna Boone DrPH RRT FAARC

Department of Respiratory and Surgical Technologies College of Health Professions University of Arkansas for Medical Sciences Little Rock, Arkansas 


\section{Parents, Teach Your Children Well}

\section{REFERENCES}

1. American Lung Association. Hookah smoking. A growing threat to public health. 2011. http://www.lung.org/stop-smoking/tobaccocontrol-advocacy/reports-resources/cessation-economic-benefits/ reports/hookah-policy-brief-updated.pdf. Accessed April 29, 2015.

2. Centers for Disease Control and Prevention. Hookahs. 2013. http:// www.cdc.gov/tobacco/data_statistics/fact_sheets/tobacco_industry/ hookahs/index.htm\#effects. Accessed April 29, 2015.

3. Calvanese AV, Bingham MV, Martinasek MP, Friesen BK. Understanding attitudes, beliefs, and information seeking regarding hookah smoking in parents of college students: an exploratory qualitative pilot study. Respir Care 2015;(7):959-966.

4. El-Zaatari ZM, Chami HA, Zaatari GS. Health effects associated with water-pipe smoking. Tob Control 2015;24(Suppl 1):i31-i43.
5. Neergaard J, Singh P, Job J, Montgomery S. Waterpipe smoking and nicotine exposure: a review of the current evidence. Nicotine Tob Res 2007;9(10):987-994.

6. Meier EM, Tackett AP, Miller MB, Grant DM, Wagener TL. Which nicotine products are gateways to regular use? First-tried tobacco and current use in college students. Am J Prev Med 2015;48(1 Suppl 1): S86-S93.

7. American Lung Association. Tobacco policy trend alert. An emerging deadly trend: waterpipe tobacco use. 2007. http://www.lung.org/stop-smoking/tobacco-control-advocacy/reports-resources/ tobacco-policy-trend-reports/2007-tobacco-policy-trend.pdf. Accessed April 29, 2015.

8. Abughosh S, Wu IH, Rajan S, Peters RJ, Essien EJ. J Am Coll Health 2012;60(7):528-535. 